\title{
Por uma história indômita: em busca de um conhecimento integrativo da Alemanha nazista antes da Guerra
}

\author{
Pedro Spinola Pereira Caldas*
}

FRIEDLÄNDER, Saul. A Alemanha nazista e os judeus, volume I: Os anos da perseguição, 19331939. Tradução de Fany Kon et al. São Paulo: Perspectiva, 2012.

A historiografia sai de sua rotina habitual de debates não somente quando uma obra teórica questiona as estruturas da produçáo do conhecimento: provocaçóes reflexivas também podem vir de pesquisas empíricas capazes de nos relembrar de aspectos fundamentais da pesquisa geralmente esquecidos e até mesmo reprimidos na e pela prática cotidiana. É este o caso da monumental obra de Saul Friedländer sobre a perseguição e o extermínio de judeus na Alemanha durante o governo nazista, finalmente editada no Brasil em dois volumes pela Perspectiva.

O segundo volume, denominado $O s$ anos de extermínio, parece ter gerado debates teóricos mais intensos do que o primeiro, Os anos da perseguiçáo, conforme se pode perceber por várias publicaçóes recentes, das quais destacaria o fórum publicado na History \& Theory em sua edição de outubro de 2008 e o recente livro editado por Christian Wiese e Paul Betts no qual vários historiadores discutem a importância de A Alemanha e os judeus (cf. BETTS, Paul; WIESE, Christian (Ed.). Years of persecution, years of extermination: Saul Friedländer and the future of Holocaust studies. Londres; Nova York: Continuum, 2010). Todavia, há razóes para também fazer bom proveito teórico de Os anos da perseguição.
E isto não seria de se estranhar, pois há algum tempo Saul Friedländer já torna mais densa e complexa a reflexão sobre a historiografia. Bastaria falar de Probing the limits of representation, livro organizado por Friedländer no qual estáo trabalhos sobre o problema da representaçáo do Holocausto, apresentados por historiadores que não necessariamente eram especialistas na história do Terceiro Reich (cf. FRIEDLÄNDER, Saul (Ed.). Probing the limits of representation: Nazism and the 'Final solution'. Cambridge, MA; Londres: Harvard University Press, 1992). Nesse livro, Friedländer já se mantinha fiel ao seu ponto de partida teórico na discussáo sobre o assunto, qual seja, o de que o Holocausto náo deveria ser apenas mais um tema entre os temas a ser tratado como "business as usual". A pesquisa documental e bibliográfica deveria ser acompanhada por uma elaboração aprofundada sobre o conhecimento histórico, e o equilíbrio entre a prática empírica e a reflexão conceitual deveria ser buscado para que esteja à altura tanto da singularidade terrível do acontecimento quanto de sua relevância universal. Evidentemente, como aponta o prefácio de Roberto Romano à edição brasileira (carente, aliás, de uma revisão mais cuidadosa, sobretudo na digitação de siglas), o antissemitismo nazista é um alerta constante para a vida contemporânea, e, neste sentido, seu estudo carrega inevitavelmente uma conotação moral, o que poderia ser entendido como um "exemplo negativo" cuja possibilidade de retorno deveria ser imediata e severamente combatida e

\footnotetext{
* Doutor em história social da cultura pela Pontifícia Universidade Católica do Rio de Janeiro, professor adjunto da Universidade Federal do Estado do Rio de Janeiro. Rio de Janeiro, RJ, Brasil. E-mail: pedro.caldas@gmail.com.
} 
mesmo criminalizada. Mas talvez seja necessário ir mais além e, por esta razão, perguntar quais são estes pressupostos muitas vezes inquestionados dos quais somos (re)lembrados após concluir a leitura de $O s$ anos da perseguição.

Heuristicamente, o livro já apresenta na introdução seus propósitos. De família judaica e nascido em Praga na década de 1930, Friedländer (que se chamava entáo Pavel, e não Saul) assume que seu relato - assim como de muitos outros historiadores especializados no tema - não se dissocia de sua experiência pessoal: "A única história concreta que pode ser resgatada permanece aquela contida nas histórias pessoais. Do estágio da desintegração coletiva ao da deportação e da morte, essa história, a fim de poder ser em última análise escrita, deve ser apresentada como a narraçáo integrada destes destinos individuais" (p. 33). Este é um tema teórico fundamental: uma história integrada que contribua e torne mais complexa a clássica discussão entre funcionalistas e intencionalistas, entre aqueles que compreendem a história da Alemanha nazista como uma "torrente caótica" que culminaria no Holocausto como uma série de decisóes que se atropelaram e culminaram em uma das maiores catástrofes da história humana ou em um plano racional muito bem executado por Hitler, pela elite partidária e pela estrutura burocrática do estado alemáo. O objetivo de Friedländer não consiste em requentar o debate, mas em sugerir a necessidade de se ultrapassar tais coordenadas reconhecendo a importância de ambas as posiçóes. Sua diferença está em propor uma narrativa integrativa capaz de "(...) justapor níveis inteiramente diferentes da realidade - por exemplo, debates nos níveis mais altos sobre a política antijudaica e decisóes próximas às cenas rotineiras de perseguição" (p. 32). A história, portanto, se dissolve enquanto objeto (distinto de um sujeito e controlável por este), perdendo seus recortes e delimitaçóes mais habituais. Escorregadia e fluida, a experiência não se deixa aprisionar em um conjunto previamente estabelecido de fontes e procedimentos.

Todavia, a bibliografia sobre o antissemitismo durante o Terceiro Reich aumenta na medida em que diminui o número de seres humanos que testemunharam, sofreram (ou cometeram) os horrores ocorridos na Europa entre 1933 e 1945. Se, de um lado, o sofrimento por ter sobrevivido à perseguição e aos campos de concentraçáo não possa ser sentido visceralmente pelas geraçóes posteriores, por outro, estas têm se dedicado a produzir mais conhecimento e mais representaçóes sobre o assunto do que nas primeiras décadas da segunda metade do século XX. Ou seja: universalizar, no tempo e no espaço, uma experiência intransponível de sofrimento pode de fato ser arriscado, mas é necessário dada a importância do evento. É este um primeiro ponto importante da obra: torná-la universal, integradora, sem que isto implique uma abstração conceitual que retire dos acontecimentos sua força e seu impacto. A integraçáo almejada por Friedländer se dá, portanto, entre vozes de algozes e vítimas e entre locais ao se deslocar pela Europa e até pelos EUA, mas também entre camadas temporais. E isto se percebe na costura do texto, ora apoiado em fontes de época, mas também na imensa bibliografia já produzida. Vozes de testemunhos e vozes, digamos, "historiográficas" se cruzam constantemente; o movimento diacrônico do texto náo avança sem um cuidadoso deslocamento sincrônico. Em Friedländer, a narrativa jamais se separa da operação crítica, e as fontes, produzidas por historiadores profissionais ou por testemunhos, lhe dão material confiável não antes da escrita, mas justamente a partir da escrita. A forma, portanto, é fundamental para a compreensão da obra.

O livro está dividido em duas grandes partes: "Um começo e um fim" e "A armadilha", e ambas contêm cinco capítulos. É na primeira parte que o autor apresenta sua interpretaçáo, a saber, a de que a perseguição aos judeus e o posterior extermínio nos campos de concentração podem ser explicados pelo que o autor chama de antissemitismo redentor. Fundamentado no conceito de religião política desenvolvido por Eric Voegelin, Friedländer afirma que “(...) uma visão de mundo tal como definida por Hitler era uma espécie de arcabouço semirreligioso que envolvia objetivos políticos imediatos. $\mathrm{O}$ nazismo não era um mero 
discurso ideológico: ele era uma religião política que demandava o mesmo compromisso total exigido por uma fé religiosa” (p. 114).

Para desenvolver seu argumento, Friedländer articula diferentes camadas, repletas de detalhes que não podem ser resumidos. Vale a pena, porém, descrever o impasse em torno à vida dos judeus na Alemanha já antes da Primeira Guerra, quando, de acordo com Friedländer, é visível o esforço, sobretudo da elite judaica, em se integrar à cultura alemã: "Os líderes e rabinos esclarecidos nunca se cansaram de enfatizar a importância da Bildung e da Sittlichkeit" (p. 127). Mas, segundo Friedländer, teria sido justamente este esforço, acompanhado de uma devida ascensão social, a gerar uma contrapartida hostil: "Os liberais exigiam que, em nome dos ideais universais, os judeus aceitassem o completo desaparecimento de sua identidade específica como grupo; os nacionalistas, por outro lado, exigiam esse desaparecimento em benefício de uma identidade particularista mais alta, a do Estado-nação moderno. Embora a maioria dos judeus estivesse mais que disposta a percorrer um longo caminho na direçáo da assimilação cultural e social, rejeitava o total desaparecimento coletivo" (p. 129). Grosso modo, pode-se dizer que, para o antissemita racista, o problema judaico estava justamente na diferença inexpugnável entre "judeus" e "arianos", ao passo que para o antissemita antirracial (ou seja, que negava a raça como fonte de identidade cultural e categoria de explicação histórica), o problema estava justamente na necessidade de se apagar esta diferença. Antes de as fronteiras se fecharem, e de a população judaica ser encarcerada em guetos e depois em campos de extermínio, ela havia, incialmente, se fragilizado no âmbito da representação política.

Será neste contexto que se desenvolverá a dimensão redentora do antissemitismo, um encontro entre cristianismo alemão, neorromantismo, culto místico do sangue ariano e nacionalismo ultraconservador. Essa mescla sustentaria a ideia de que "(...) a redenção da cristandade ariana seria alcançada somente pela eliminaçáo dos judeus" (p. 137), que se expressaria, a partir de Hitler, mediante uma visão simples de mundo, formulada repetida e emocionalmente, sem elaboração intelectual: "Apesar da aparência de análise histórica, o judeu, na descrição de Hitler, era desistoricizado e aparecia como um princípio abstrato do mal (...)" (p. 150).

Todavia, Friedländer mostra com clareza como o antissemitismo redentor não é um conceito que simplesmente se desenvolve idealmente na história; a perseguição aos judeus se deu em uma mistura de sentimento de ódio e um devido cálculo pragmático; afinal, o governo de Hitler precisava, também, estabilizar a economia alemã, e, por isso, "entre 1933 e 1936, havia certo equilíbrio instável entre o impulso carismático-revolucionário do nazismo e as tendências conservadoras e autoritárias do Estado alemão anterior a tal período" (p. 167). E mais ainda: era necessário, também, levar em conta a própria sociedade civil, que nem sempre estava disposta a aprovar a violência contra os judeus, ou a se privar dos serviços habitualmente fornecidos por eles (p. 177-183). O equilíbrio, portanto, entre Hitler, o partido, a burocracia estatal e a sociedade civil era bastante delicado, mas viria a encontrar nas Leis de Nuremberg um ponto de sustentação decisivo: como argumenta Friedländer, a "objetivação" legal da situação dos judeus na Alemanha tornou, aos olhos da população, mais definido seu lugar. Uma vez definido o grau de segregação, seria igualmente demarcado o momento em que a violência contra os judeus não seria mais aceita. Mas este marco (da não aceitaçáo) seria agora objetivado pela lei, e não por uma ação autônoma, mesmo a mais tímida, da sociedade.

$\mathrm{Na}$ segunda parte, o livro apresenta sua história integrada de diferentes maneiras: em uma delas, o autor nos mostra como a perseguição se intensificaria paralelamente à estabilização econômica da Alemanha. É um argumento fundamental, pois mostra justamente como o antissemitismo tem autonomia como força motriz da história, ou seja, ele náo é reflexo de crises econômicas, o que também não implica que não tenha conexões com a vida material.

Se foram complexas as relaçóes do nazismo com as atividades econômicas, não o seriam menos com as espirituais, ou, mais precisamen- 
te, com as instituiçóes religiosas dentro e fora da Alemanha. No Vaticano, mesmo a dura crítica de Pio XI, registrada em sua encíclica Mit brennender Sorge, apontava para a existência de limite na capacidade de resistência às iniciativas do governo alemão: "a pseudorreligiāo nazista e as teorias raciais do regime eram rigorosamente condenadas em termos gerais, todavia não era feita nenhuma referência direta ao destino dos judeus" (p. 254). Hitler manteria, por exemplo, alguma prudência no planejamento da eutanásia, algo que encontraria resistência nas Igrejas, sobretudo, a Católica. Mas bem menos complexo parece ter sido o contato do nazismo com o mundo acadêmico, que sem dificuldades se adaptaria, desde 1933, à nova situação política. Um meio termo entre a cultura intelectual e o mundo cristáo pode ser medido, se seguirmos o argumento de Friedländer, a partir de autores como Georges Bernanos, T. S. Eliot e G. $\mathrm{K}$. Chesterton, que não deixavam, cada um a seu modo, de manifestar seu antissemitismo, ainda que sob o manto da crítica da cultura, da denúncia da crise da civilização.

A história integrativa de Friedländer atinge seu ponto alto quando mostra, em grande escala, o destino dos judeus na Europa, mais precisamente na França, na Polônia e, sobretudo, na Áustria. Se até aquele momento acompanhamos a formação de diferentes nuvens negras que cobrem a Europa, será a partir da anexação da terra natal de Hitler ao território do Reich que a perseguiçáo aos judeus começará a adquirir contornos mais definidos e organizados. Com o confisco de propriedades e sua subsequente inviabilização econômica, a vida dos judeus, a partir de março de 1938, passou a ser impossível na Áustria. Os refugiados tornavam-se realmente um problema internacional, e a conferência de Evian, na França, em julho do mesmo ano, não resolveria de forma alguma o impasse. Este é um momento decisivo, pois o horror dos campos de concentraçáo durante a Guerra por vezes nos obriga a lembrar que, em 1936 e 1937, cerca de 7.500 pessoas estavam presas nos Lager, sendo a maioria delas “(...) membros de seitas religiosas, como as Testemunhas de Jeová, homossexuais e 'criminosos habituais' ou 'antissociais' (...)" (p. 270). E, na Alemanha, ainda em 1937, “(...) as relaçóes econômicas entre judeus e alemães ainda permaneciam ativas em vários domínios, como, por exemplo, membros da aristocracia, do corpo de oficiais e da alta burguesia ainda mantendo seus ativos em bancos judaicos" (p. 305).

A integração narrativa se faz sentir em sua capacidade de estabelecer relaçóes que náo se reduzem a uma concepção organicista da história. A metáfora de Friedländer da "formação da tempestade" é bastante rica: nuvens se sobrepóem, mas também deixam pedaços de céu aberto, têm diferentes tamanhos, e futuramente mostrariam forças de intensidade desigual. Mas, sem dúvida, apesar de ritmos distintos, o que se anunciava era uma tempestade que mudaria o cenário europeu e mundial. Hitler tomava medidas concretas para o início da Guerra, o que fez com que a composição interna do governo mudasse, com a substituição de ministros conservadores por outros plenamente identificados com o partido.

A articulação de diferentes níveis, seja no âmbito nacional alemão, seja no continental e mesmo transcontinental, dá ao livro de Friedländer uma estrutura labiríntica, estonteante até. São muitas as vozes que se sobrepóem, se cruzam, se alternam. Náo é possível encontrar uma causa capaz de organizar hierarquicamente a explicação do antissemitismo. Qualquer fundamentação econômica, social ou política que apresente a perseguição e o extermínio como subprodutos determinados terá o efeito analgésico de nos satisfazer com uma compreensão das motivaçóes que levaram sofrimento a milhôes de vidas. A integração não será totalizante, ou mesmo estruturante, no sentido de operar uma redução conceitual das experiências, mas sim ao ser capaz de gerar desconforto.

Talvez esteja aí o grande valor teórico do livro: produzir outro foco para a discussão teórica envolvendo o Holocausto. Já são abundantes os debates sobre os limites da representação (para os quais, como vimos, contribuiu o próprio Friedländer), mas talvez fosse o caso de pensá-los por outro ângulo, talvez por uma dimensão ética mais radical, a saber: a de se evitar a domesticação do passado. A constante mudança de registro, a alteração entre 
histórias singulares e as grandes linhas da política internacional, entre testemunhos individuais e dados estatísticos geram o efeito desejado por Friedländer, ou seja, mais do que compreender e explicar, estabelecer uma “(...) relação entre o incomum e o habitual” (p. 33).

Reflexivamente, se ganha bastante com $O s$ anos da perseguição: a psicanálise pode oferecer mais do que um instrumentário conceitual envolvendo o conceito de trauma - afinal, aqui não caberia pensar esta relação entre o "incomum e o habitual" a partir do conceito de Unheimlich, o incômodo, de Sigmund Freud? Habitualmente traduzida como "o estranho", a ideia de que há uma negação (in) em algo conhecido (cômodo), isto é, de que pessoas comuns cometeram atos incomuns, é o que precisa ser exposto. Neste sentido, seria capaz a historiografia de Friedländer de produzir uma ferida narcísica na imagem que o homem ocidental faz de si mesmo?

Mas se talvez ainda não seja o momento de dar respostas, é inegável que, em Os anos da perseguição, Friedländer pretende escapar do risco de domesticar o passado. Creio que seja esta uma chave de leitura muito rica para seguir na leitura de seu segundo volume, $O s$ anos de exterminio. De qualquer forma, atravessar este primeiro é fundamental para ver como o incômodo já se revela antes mesmo do período mais tenebroso do século XX. 